\title{
TAALGEBRUIK - SENSUUR OF NIE?*
}

\subsection{Vooraf}

Dit gaan hier, redelik oppervlakkig-populêr, oor taalhoudings en enkele knelpunte rondom taalgebruiksbeoordeling. Ek wil vooraf kortliks 'n paar opmerkings oor tegniese taal en vakterminologie maak, vóórdat ek iets meer in die algemeen gaan sê oor taalsuiwerheid en Anglisismes.

My gesprek oor vaktaal wil ek knoop aan enkele aanhalings uit 'n paar wetenskaplike werke, wat as tipiese voorbeelde moet dien. Ek spreek ook nie noodwendig kritiek op dié taalgebruik uit nie.

A.

"In sinne soos (i) 'kongrueer' die 'verbum' met die afgeleide 'Subjek', byvoorbeeld the bananas, en nie met die onderliggende subjek, byvoorbeeld the monkey nie."

En van dieselfde skrywer:

B.

„Dit sal spoedig hieronder blyk dat RG een van die 'potensieel' mees 'signifikante', mees kontroversièle - en dus mees interessante - pogings tot sintaktiese teorievorming van die afgelope vyf jaar kan word."

C.

"Teofillien rem weer die 'hidrolise' van die 'SAMP', deur remming van die 'fosfodiesterase-ensiem' wat hierdie reaksie 'kataliseer', en verhoog sodoende ook die "SAMP'-vlak."

D.

"In hierdie referaat word op 'n bepaalde aspek van die onderhoudsvoerder

* Hierdie artikel is as referaat voorgedra voor die Vereniging vir taal- en letterkunde, PU vir CHO, onder die titel Lees maar - er staat wat er staat. Die gedagte met die nuwe titel is om die aandag te vestig op die kwessie of ' $n$ mens by dic beoordeling van ' $n$ bepaalde taalgebruiksgeval met 'n beoordeling van 'buite' te make het, dus as 't ware met 'n soort (voorskrywende) taalsensuurwet, of eerder met 'n beoordcling van 'binne', dus met 'n soort regstellende taalgewete (te stel teenoor taalwete) - en verder, of hicrdic beoordeling van buite, dit wil se hierdie taalwet, tog wel berus op ecn of ander taalnorm, dit wil sê of dit 'n wetenskaplike weerspicéling is van die norm van die taalgemeenskap. Dié saak kan miskien direkter in 'n volgende artikel uitgewerk word. 
se gedrag 'gefokus', naamlik sy wyse van 'relatering' of 'kontak' maak met die ander, en die 'teneur' van my betoog is dat 'sensiticwe relasicvorming' 'n 'konstruktiewe' bydrae lewer tot 'effektiewe' onderhoudsvoering."

(Kursivering deur my $-\mathrm{HF}$.)

1.1 Dit is gangbaar onder taalwetenskaplikes om te onderskei tussen woord en term. Waar die woord volksgoed is, algemene besit, veelduidig in betekenis en algemeen bruikbaar, vloeiend soos lopende water, is die term nicvolksgoed, (een-) eenduidig in betekenis; dus op wetenskaplike wyse goed gedefinieer en slegs bruikbaar (amper soos 'n óórgeteelde bul) binne sy he doelde vakgebied - solied soos 'n blok geysde water.

Oor die voorgaande uitlating wil ek net twee opmerkings maak:

1.1.1 Nòg woord, nòg term beteken sò presies as waarop die algemene taalgebruiker op hoop of reken. Vergelyk byvoorbeeld wat Rudolph (1977: $113,114)$ in sy artikel Taal as werktuig sê:

„Die digter en die wetenskaplike wil dit, elk op sy eie manier, as presisie-instrument gebruik; die demagoog gebruik dit as voorhamer, die satirikus as lanset, en nog 'n digter speel daarmee. Dit is 'n uiters nuttige instrument - juis vanweë sy veeldoeligheid en veelbruikbaarheid. Altyd paraat, maar selde akkuraat.

Ortega y Gasset is oortuig daarvan ,... dat spreken een veel bedrieglijker handeling is dan men gewoonlijk meent."

Hy wys dan ook op die ontoereikendheid van taal en verklaar: ,Zij zegt ... gedeeltelijk wat wij denken en vormt een onoverkomelijke belemmering voor de doorzending van de rest (k.v.m.).

Juis vir diegene wat in ' $\mathrm{n}$ tegnologiese eeu aan 'n nie-eksakte vak die begeerde status van ' $n$ wetenskap wil gee, is die volgende van pertinente belang:

'Naarmate het gesprek overgaat (van wis- en natuurkunde) naar belangrijker menschlijker, 'werkelijker' onderwerpen, neemt de onnauwkeurigheid van de taal en haar traagheid van vaagheid toe".

Rudolph (1977:122) sê verder dat dit 'n wanbegrip is om te dink dat 'n mens die werklikheid met 'n woord kan vasvat:

,'n Enkele opmerking oor die wanbegrip dat hy die werklikl:eid met 'n woord kan vasvat:

Uit die voorafgaande moet dit duidelik wees dat die werklikheid (vir my altans) nie uit objekte, uit dinge met name bestaan nic. 'n Mens kan dit miskien nader aandui as ' $n$ werklikheid van strukturele vcrhoudinge. Waar die sintuiglike altyd die maksel van jou sintuie is, is die dinge wat jy sien reeds 'n halwe waarheid. Sy naam is 'n sein, 'n kode-aanduidinge van dié halwe leuen. Om nou persoonlikheid, intensionele gerigtheid, lewensruimte, en ander sake in verband met die onbekende mens met woorde te probeer vasvat, is 'n onbegonne taak. Ons herinner aan Einstein se woorde wat as motto bo-aan hierdie artikel staan:

'As far as the propositions of mathematics refer to reality, they are not certain; and as far as they are certain, they do not refer to reality'." 
Rudolph (1977:119) wys verder daarop dat:

„Dic Teorie van Informasie beweer lankal (en aanvanklik met baic wecrstand van dic kant van taalgeleerdes af) dat woorde as sodanig nic betekenisse het nie, maar dat betekenisse opgesluit lê in die ontvanger van dic boodskap se senustelsel".

Daar is natuurlik heelwat taalkundiges wat in dié rigting dink, hoewel die saak nie só ver deurgetrek word nie.

1.1.2 Dit gebeur algemeen dat die term die volksmond binnedring en woord word. (Vergelyk die, vir my, klassieke voorbeeld van die terme idioot en moroon. As term in die sielkunde dui eersgenoemde 'n persoon aan wat laer op die intelligensieskaal as laasgenoemde lê. In die volksmond is die prentjie egter mooi net omgekeerd. Dit is natuurlik heel duidelik hoe so iets kon gebeur: Elke tweede persoon word ' $n$ idioot genoem (die laagste op die intelligensieskaal), maar slegs elke vierde persoon is 'n moroon. Heel gou slyt die trefkrag (let wel dit is 'n emosioneel-gelaaide woord, waar dit nie nét om die betekenis gaan nie) van die woord idioot egter af, vanweë die feit dat dit nie meer voldoende onderskei tussen die gewone en die ongewone mens nie. Gevolglik moet moroon nou dié funksie oorneem. Die woord imbesiel is volgende aan die beurt - miskien gaan ons nog die hele lys só deur.

Vanweè die feit nou dat die term nie eksklusief bly nie (vergelyk Boshoff $(1963(a): 23$ ), het veral die termskepper (let wel: nie terminoloog nie - wat die deskundige termskepper is) myns insiens 'n verantwoordelikheid in sy keuse van terme. Op hierdie verantwoordelikheid - hoewel van toepassing op die terminoloog - wys Roux (1967:21) (van die Raad op Atoomkrag) ook in 'n lesing gehou voor die vaktaalkongres van die Akademie vir Wetenskap en Kuns.

Omgekeerd is dit natuurlik ook so dat talle doodgewone woorde ,verhef" word tot terme, of dat selfs verouderde en afsterwende woorde op dié wyse nuwe lewe ingeblaas kan word - en wel met groot welslae (kyk in dié verband byvoorbeeld Boshoff $(1963 \mathrm{a}: 21,22 ; 1963$ (b):96-104; Terblanche (1963:86-95)).

Ek het vroeër gesê dat dit gangbaar onder taalkundiges is om te onderskei tussen term en woord. Net so word aangeneem dat elke vakgebied dan sy eie vakterminologie het - dus die som van al sy vir-sy-eie-gebied gedefinieerde terme.

Ek wil egter die bewering maak dat elke vakgebied (of groepe vakgebiede gesamentlik) elk sy eie (hulle eie), durf ek dit maar noem "nomenklatuur" het - dit wil sê eie ,voorkeurwoordeskat". Op sigself is so 'n opmerking nie snaaks nie, omdat hierdie saak gewoonlik oor dic hoeg van 'n styl gegooi word. Hier is naamlik sprake van 'n sogenaamde wetenskaplike of 
hoogs tegniese styl. Die punt wat ek egter wil stel, is dat daar, waarskynlik tot die heil van Afrikaans, behoort onderskei te word tussen egte terme en voorkeurwoorde.

Kyk weer na die vakwetenskaplike aanhalings hierbo: potensieel in plaas van moontlik; signifikante in plaas van betekenisvolle/belangrike; kontroversiële in plaas van ?; gefokus in plaas van belig/aandag vestig, konstruktiewe in plaas van opbouende, ensovoorts.

Let goed op dat dit hier nie gaan om terme nie, maar om woorde. Daar sou geen afbreuk gedoen gewees het (aan die formele boodskap) indien die ooreenstemmende ,"suiwer Afrikaanse" woord gekies sou gewees het nie of sou die "aroma" van wetenskaplikheid dan dalk aangetas word - of het ons werklik 'n stilisties, dus wérklik taalmatige motivering hiervoor? (Die kwessie van taalsuiwerheid word later weer aangeraak.)

My persoonlike mening omtrent hierdie saak (prof. Hertzog Venter huldig ook dié standpunt) is dat die Germaanse woord die voorkeur bo die Romaanse of klassieke moet kry - in elk geval wat die nomenklatuur-/voorkeurwoordvlak betref. Die probleem met ons voorkeure, selfs vir die sogenaamde Romaanse of klassieke, is dat dit deur middel van Engels by ons uitkom. So 'n standpunt hou natuurlik sy eie implikasies in, waarop ek nie nou kan ingaan nie.

Oor die vakterminologie het Rudolph $(1977: 120,121)$ verder die volgende te sê:

„Die skep en die aanvaarding van 'n bepaalde vakterminologie is miskien heelwat minder van 'n seën as wat ons wil toegee. Saam met die terme gaan die strukturele onderstellings waarop die sisteem gebou word. Wie dus die taal aanvaar, aanvaar ook die stil, onuitgesproke onderstellings. Die ongeseënde gevolg hiervan is dat enige mens wat iets bedink en sy denksels in taal geformuleer het, alewig die gevaar loop om nie net die ge vangene van sy eie taal te word nie, maar via die taal ook die gevangene van sy eie bedinkte on ver-taalde strukturele onderstellings. As die 'gevangene' 'n onderwyser of lektor is, word diegene wat na hom luister sy medegevangenes. En as hy baie oortuig is - sy arme slagoffers. (Denke geskied soms sonder taal. Dink aan die skaakspeler, of Einstein se eie getuienis in ......)

Die studente wat 'n nuwe vak neem, die man wat by 'n ander universiteit inskryf en met 'n ander "skool" se woorde en denkbeelde te doen kry, is by voorbaat gedoem om nou ook so te 'dink'. Hy moet nou leer om die geluide te maak wat van hom verwag word, anders pas hy nie in dié skool se raanwerk nie. Die meeste akademiese skole soek ongelukkig eerder proseliete as eerlike navorsers. (Ek is bereid om te erken dat laasgenoemde sin nie ' $n$ wetenskaplike opmerking is nie; dit moet nog geverifieer woord!)".

U sou nou seker reeds opgemerk het dat dit vir ons in kommunikasie op tegniese gebied (trouens, in enige taalkommunikasie) gaan om én verstaan- 
baarheid én aanvaarbaarheid. Hieroor later meer.

Ek laat dus nou die kwessie van vakterminologie vir eers daar.

\subsection{Anglisismes, taalsuiwerheid en ander kwessies}

2.1 Ek sou nou graag u „taalgevoel” oor die volgende gevalle wou toets watter van die volgende gevalle sou $u$ as nie-Afrikaans beskou?

A. die rivier is is vol, die rivier is in vloed; wag vir iets, wag op iets; aan boord skip, aan boord van die skip (De Bruto, 1970:39);

B. hand skud, handdruk gee; dit vat tyd, dit kos tyd; meen, voel (sonder my), slippers, agter die kinders kyk, roep ('noem'), dagbreek, perdeskoen (Boshoff, 1921:421). Hieroor maak Boshoff die volgende opmerking: „As voorbeelde van wat gewoonlik in Afrikaans as Anglisismes aangesien word, maar dit waarskynlik nie is nie, noem hy (Schonken - HF) op: ...";

C. baie van die voorbeelde is gefabriseer, ek wil jou filisiteer, hierdie stuk is ajent aan, watter prevensie kan daarteen geneem word?, gaan bêre jou bycicle en bring die toorts hier;

D. dit, ek sal nie weet, watter gaan dit om.

$\mathrm{U}$ het so pas uitspraak oor bepaalde gebruiksgevalle gelewer. Die vraag wat nou eerste opduik, is: Op grond waarvan het u dié uitsprake gemaak, dit wil sê wat was u gesagsbron?

2.2 Die antwoord kan miskien so geformuleer word:

1. op grond van my intuitiewe (moeder-)taalgevoel. (Ek sou dit verkies om in hierdie verband eerder die term taalwete te gebruik. Oor die term taalgevoel word dan later weer gese.);

2. op grond van my kennis óór (let wel: oor en nie van nie) Afrikaans en/ of op grond van my kennis oor Anglisismes.

Sonder om voorlopig verder op hierdie aangeleentheid in te gaan, wil ek u aandag egter spesiaal daarop vestig dat die volgende moontlikhede nou kan opduik :

1. U taalwete het ' $n$ voorbeeld as Afrikaans aanvaar, terwyl dit deur een of ander taaldeskundige as ' $n$ Anglisisme bestempel is.

2. $U$ taalwete het ' $n$ voorbeeld as nie-Afrikaans verwerp, terwyl een of ander taaldeskundige dit as 'n Anglisisme beskou het.

3. $U$ taalwete het ' $n$ voorbeeld aanvaar, terwyl een of ander taaldeskundige dit nie as 'n Anglisisme beskou het nie.

4. $U$ taalwete het ' $n$ voorbeeld verwerp, terwyl een of ander taaldeskundige dit nie as ' $n$ Anglisisme beskou het nie.

2.3 Ons kan op grond van dié vier opmerkings die volgende verdere afleidings mak : 
1. Hier is duidelik sprake van verskillende sóórte uitsprake.

2. Elke uitspraak berus op 'n verskillende gesagsbron - daar is dus sprake van verskillende gesagsbronne.

3. Ons het nie probleme met opmerkings 2 en 3 nie omdat ons (as moedertaalsprekendes se) taalgevoel, dit wil sê taalwetes, hier blykbaar in ooreenstemming is met die standpunt van dié taalbeskouer.

4. Daar is probleme met opmerkings 1 en 4 vanweë 'n skynbare of werklike teenstrydigheid in die uitsprake van die moedertaalsprekende en die taalbeskouer.

5. Ons as moedertaalsprekendes het 'n bepaalde "houding" teenoor sekere van hierdie taalgebruiksgevalle.

Laat ons vervolgens hierdie afleiding van naderby bekyk:

\subsubsection{Afleidings 1 en 2}

Soos reeds gesien, is hier sprake van ten minste twee soorte uitsprake: die uitsprake van taalgebruikers en die uitsprake van taalbeskouers. Anders gestel: gaan dit oor taalgebruik en die beoordeling daarvan, is daar sprake van twee soorte uitsprake, te wete:

(i) taalintuitiewe uitsprake van die moedertaalspreker (berus op die taalwete);

(ii) taalbeskoulike uitsprake van vakmanne/taalkundiges 1 ).

(i) Die probleem met dié soort wete is dat die gesagsbrong glad nie so onfeilbaar is as wat die komponent/deel wete wil weergee nie ${ }^{2}$ ). Hierdie ,wete" is in elk geval geweldig broos en raak maklik versteur. Verder is dit betreklik persoonlik, sodat kleinere of grotere verskille tussen persone rakende bepaalde gevalle, in ' $n$ mindere of meerdere mate, algemeen is.

Die tweede soort uitspraak, naamlik dié van die taalbeskouer verdien nou verdere aandag. Hier het ons in die eerste plek met 'n gesagsbron in sy eie reg te doene - in soverre die uitspraak van die vakman of taalkundige sélf

1) Ek verwys $u$ vir ' $n$ vollediger uiteensetting van hierdie kwessie na my artikel: Vry heid, gebondenheid en gesag in $n$ kursus Afrikaans, Koers, 43, 1, 1978. Dit is interes sant om daarop te wys dat Boshoff (1958) self in 'n artikel met die titel ,Vryheid en gebondenheid in taalgebruik - styl" oor dié kwessie geskryf het, maar die klem anders geplaas het.

2) Die teoretiese uitgangspunt binne die breèr algemene TGG-paradigma is steeds aan kwaai kritiek onderworpe, veral vanuit die sosiolinguistiek. 
gesagsbron word, en wél in dié mate dat hy by hierdie gesag as vakman of taalkundige verdien, en dus as sodanig deur die algemene taalgebruiker as gesagsbron beskou en aanvaar word. Die vakman of taalkundige steun natuurlik sélf in die eerste plek op sy eie intuisie (wat grootliks as norm aanvaar word, júis omdat hy een van die sogenaamde prestigegroep van die meerderes vorm wie se taalgebruik/uitsprake as norm deur die meerderheid aanvaar word), hoewel hy as taalwetenskaplike in 'n groter mate kan reflekteer oor / wetenskaplik objektief kan omgaan met wat beskou móét word as die norm - as dus korrek of nie. (Op die probleme hier rondom gaan ek nie nou in nie, maar kyk voetnoot 1 .)

Die woord norm ${ }^{3}$ ) het nou reeds verskeie kere opgeduik. Ek wil net daarop wys dat ek reken dit nodig is om in hierdie verband tussen norm en voorskrif te onderskei. norm hou dan verband met die intuitiewe taalwete van die moedertaalspreker, terwyl voorskrif verband hou met gesag wat in die taalbeskouer (vakman) setel. Laasgenoemde gesag mag (móét) egter gebaseer wees op (egte) taalnorme. Voorskrifte is ter sprake by die sogenaamde voorskrywende taalkunde. Gaan dit nou om taalsuiwerheid en sulke kwessies soos Anglisismes, dan raak ons die terrein van die voorskrywende taalkunde aan - waarmee ons in ' $n$ sekere sin hier dan ook besig is.

Om te vervat: die taalbeskouer moet dus altyd eerlik en opreg die egte taalnorm probeer peil - hoewel ook ander nie-taal vorme toegepas mag word. So mag die taalsuiwerheidseis/beginsel vir die voorskrywende taalkundige belangrik wees, maar, soos ons reeds gesien het, val hierdie kwessies heel dikwels juis buite die taalgebruiker se taalwete, sodat laasgenoemde dan volkome op die voorskrif van die vakman sal moet terugval.

Op hierdie wyse mag die vakman, nádat hy in die omvattender taalsis. teem gaan delf het - wat heel dikwels 'n historiese studie, insigte en kennis van die taal behels, as 't ware op heel kunsmatige wyse sekere voorskrifte aan die taalgebruiker voorhou.

'n Konkrete voorbeeld: $U$ taalwete (as taalgebruiker) help u nie by ' $n$ keuse tussen op vakansie en met vakansie nie, maar tog dwing die suiwerheidsbeginsel $u$ om 'n keuse te maak. $U$ kan nou blindelings en onwetenskaplik reageer deur op vakansie te gaan vermy, bloot omdat daar 'n Engelse vorm daarnaas bestaan wat baie so lyk.

3) Ek besef dat die woord norm hier veelduidig raak, en dit het heelwat taalkundige implikasies. Dit is egter 'n saak wat later uitge werk sal moet word. 
Die vakman moet egter wetenskaplik bevestiging kry, ten einde 'n gemotiveerde voorskrif - een wat berus op 'n egte taalnorm - daar te stel. Omdat die huidige geslag se taalwete nie kan help nie, bestudeer hy ouer Afrikaans en bewys dan objektief dat met vakansie eerste daar was en dat op vakansie ná kontak met Engels in Afrikaans ingekom het. Hier het ons dus met taalverandering te make, en nou gaan dit nie net daarom om verandering as sodanig negatief te veroordeel nie, maar dit gaan daarom dat die verandering as negatief ${ }^{4}$ ) beóórdeel word, deurdat dit onder invloed van Engels geskied en Afrikaans dus in die rigting van Engels buig.

Dit gaan dus nie hier om die langhaar - of pop-is-goed-redenasie nie, waarin eersgenoemde alle verandering op sigself as sleg, en laasgenoemde alle verandering as goed beoordeel. Dit is terloops 'n feit dat ' $n$ taal wat verander, júis ' $n$ lewende taal is. ' $n$ Taal is lewend indien dit kultuurbesit is van ' lewende volk wat dit as sy omvattende kommunikasiemiddel gebruik. Kyk byvoorbeeld Le Roux (s.j.:35) in dié verband.

\subsubsection{Afleiding 3}

Hieroor is daar verder niks te sê nie.

\subsubsection{Afleiding 4}

Dit gaan hier om probleme wat 'n mens mag hê wanneer die taalgebruiker en die taalbeskouer se uitsprake nie meer ooeenkom nie. Hier het 'n mens dan eintlik met 'n gesagskrisis te make en behoort die vakman (egte vakman en nié skoolvos ${ }^{5}$ ) ) se oordeel aanvaar te word.

Die redes hiervoor is voor-die-hand-liggend:

1. Elke taalgebruiker mik na 'n sekere norm - dit is eintlik deel van sy bekomde/verworwe taalwete. Die norm setel in die spraak van die meerderes en die taalvakman hoort sekerlik tot dié meerderes wat die taal betref.

2. Iie vakman self beskik óók oor 'n taalwete, en omdat hy deskundige op

4) Oor die kwessie 'negatief' later meer.

5) $\mathrm{MJ}$. Posthumus, afgetrede professor in Afrikaans-Nederlands, van Unisa, het altyd met so $h$ vonkel in die oog vertel dat as mense hom genader het oor sake soos Anglisismes, en of ' $n$ bepaalde geval nou 'n Anglisisme is of nie, hy hulle altyd met hierdie woorde wegge stuur het: „Ek weet nie, gaan vra jou eksaminator". 
die gebied van die taal is, beskik hy nie alleen oor kennis van sake nie, maar het hy ook 'n fyn aanvoeling vir sy taal ontwikkel. En verder: omdat hy vakman/taalkundige is, kon hy die ter sake aangeleenthede makliker waarneem en wetenskaplik daaroor besing, dit wil sê makliker oor sy taal reflekteer.

\subsubsection{Afleiding 5}

Hier gaan dit daarom dat elke mens 'n houding teenoor sy taal het of hy is taalgevoelig, dit wil sê het 'n gevoel vir sy taal en probeer dit suiwer en goed gebruik, òf hy gaat maar door.

Om oor hierdie saak wetenskaplik te praat, verg beslis 'n kragtiger model as dié van Chomsky (1965) en selfs dié van sosiolinguiste soos Hymes en andere $^{6)}$.

Sosiolinguistiese modelle soos dié van Fishman (1969), wat baie sterk sosiologies geneig is, maak egter voorsiening vir sulke sake soos taallojaliteite ensovoorts - waaroor dit eintlik hier gaan.

Dit gaan naamlik wanneer dit oor sulke sake soos Anglisismes gaan, om taallojaliteit, oor houding teenoor jou taal, oor taalgevoeligheid. Ons het hier te make met nie-verstandelike sake, irrasionele sake.

Dit het nie te make met jou taalwete, of selfs kommunikatiewe ${ }^{7)}$ wete nie.

Hierdie spesiale houding/gevoel teenoor jou taal kom byvoorbeeld ter sprake by taalverandering. Soos reeds gesê, dui verandering as sodanig nie op iets negatiefs nie, maar eintlik op iets positiefs, deurdat 'n taal wat verander, 'n lewende taal is. Wanneer hierdie verandering egter negatief deur die taalgebruiker en/of taalbeskouer beoordeel word, dan kom hierdie houding wél ter sprake.

Dit is presies die geval met ons lojaliteit teenoor Afrikaans. Hier is naamlik sprake van verandering van Afrikaans. Dié verandering is egter as gevolg van taalkontak. Taalkontak lei tot taalbeinvloeding en taalbeinvloeding tot taalverandering - en wel in die rigting van die beïnvloedende taal. Die beinvloedende taal wat hier ter sprake is, is Engels, en Engels (eintlik 'n $\wedge \mathrm{r} g$ le-

6) Vergelyk voetnoot 1.

7) Vergelyk onder andere Hymes (1971) in: Pride \& Holmes (eds.) 1972 in verband met dic begrip 'communicative competence'. 
wêreld) word as 'n bedreiging deur die taalgebruiker beoordeel.

Dit is egter wél so dat kommunikasie, wat die blote oordrag van inligting as sodanig betref, nie noodwendig belemmer hoef te word as 'n taal (Afrikaans) deurspek is met Engelshede en Anglisismes nie. Met dié argument kom baie mense in die trant van: "Why worrie, ons kommunikeer mos". Tog kan dieselfde persoon wat só praat, maklik hewig ontstel word deur enkele modderspatsels op sy skoenpunte, en is sy huis se geute nie afgedop en geroes nie.

Die punt is net dat taal méér is as blote inligtingoordragmiddel - dit is kommunikasiemiddel in die wydste sin. Dit is dus geestesbesit, kultuurbesit en eiebesit van die hoogste orde.

(Net soos 'n mens jou erfenis, en veral jou kultuurerfenis - in besonder dié wat duidelik materièle vorm aangeneem het, byvoorbeeld die ou stoel of motorkar - vertroetel, so ook, en soveel te meer jou taal, jou hoogste kultuurerfenis.

Dít is die vlak waarop 'n mens oor die suiwerheid van jou taal ,voel". Dit raak die kwessie van waardesisteme: eiewaarde, die estetiese, ensovoorts, maar dit raak selfs die nasionale gevoel. Hierdie gevoel teenoor die eie, en die gevolglike reaksie teen die vreemde, hoef nie (nét) negatief beoordeel te word nie - dit behels júis die positiewe: die bewaring van die eic maak dit dadelik sinvol dat die ander ook so voel oor sý eie, en wat só meehelp tot die skep/bestaan van wedersydse respek - iets wat ons in hierdie land van ons vandag so broodnodig het, veral in ons brose volkereverhoudings. En ons kan gerus weer gaan dink oor die posisie van die Swartes, en sý taal.

\subsection{Ten slotte}

Ek wil ten slotte dan nou iets meer regstreeks oor Anglisismes as sodanig sê.

'n Anglisisme word deur talle taalkundiges beskou as 'n bousel in Afrikaans, wat onder die invloed van Engels staan - en wel negatiewe invloed. Negatief dui hier: 
1. op ' $n$ verdringing van die eie, en/of

2. op 'n botsing met die Afrikaanse sisteem.

\subsubsection{Enkele opmerkings}

1. Verdringing van die eie impliseer 'n historisiteitsnorm, en soos gesien, help die taalwete selde hier. 'n Taalkundige sal dus met 'n studie van buite moet kom help.

2. Die bots met die Afrikaanse sisteem lewer ook probleme omdat bots met en sisteem hier naderby gespesifiseer sal moet word.

\subsubsection{Goue reëls by die kwessie van Anglisismes}

1. Geen leek (of selfs deskundige) behoort 'n geval sonder meer (bloot op die sigwaarde) as 'n Anglisisme te tipeer, alvorens dit met empiriese feite gestaaf $k$ an word nie.

2. Ontwikkel u taalgevoel en taalwete (met smaak), en vermy dan vorme wat volgens u taalwete dui op Engelse invloed. (Opmerking: Dit is vanselfsprekend dat daar op hierdie wyse dalk egte Afrikaanse vorme in die slag mag bly, maar solank $u$ u eie taalwete sterk ontwikkel en $u$ met omsigtigheid en met 'n positiewe ingesteldheid te werk gaan, deur byvoorbeeld samespraak met $u$ ander taalgenote en -vakmanne te hou, sal die voordele veel meer as die negatiewe gevolge wees. Trouens - 'n mens moet daarop bedag wees dat enige genesende program (remediërende program) sy eie negatiewe bygevolge inhou. U behoort ook nou nie meer te hewig ontstel te wees as Van der Merwe (1967:28) as sulks afkeur as onder Engelse invloed, maar Le Roux (1975:14) (self 'n fyn, gevoelige taalgebruiker en taalkundige) dit wél gebruik nie. (Dit is net jammer dat Van der Merwe as sulks gaan tipeer het as 'n Anglisisme - myns insiens het hy sy saak nie empiries ondersteun nie.) In elk geval: $u$ is nie net naprater nie, maar ook taalskepper in eie reg.

('n Laaste opmerking: Ek kan dit nie nalaat nie om $u$ te verwys na 'n absoluut skitterende artikel van J.C. Steyn (Jaap): Die Afrikaner en Afrikaans, in $T G W .17,3$ en waarin hy Afrikaans as taal van die Afrikaner, in die breè én in die diepte bekyk.) 


\section{WERKE WAARNA VERWYS IS}

BOSHOFF, S.P.E. 1921. Volk en taal van Suid-Afrika. Amsterdam, De Bussy.

BOSHOFF, S.P.E. 1958. Ons en ons taal. SAUK-uitgawe.

BOSHOFF, S.P.E. 1963(a). Mense van gister, vạndag en môre. Johannesburg, Voortrekkerpers.

BOSHOFF, S.P.E. 1963(b). Die woordeskat van Afrikaans, in: BOTHA (red.) 1963. BOTHA, T J.R. 1963. Taal en teken. Kaapstad, Academica.

CHOMSKY, N. 1965. Aspects of the theory of syntax. Cambridge, Massachusetts, MIT Press.

DE BRUTO, H.F. 1978. Vryheid, gebondenheid en gesag in 'n kursus Afrikaans. Koers, 43.1

FISHMAN, J. 1969. Sociolinguistics. In K.W. Back (ed). Social psychology. New York, Wiley.

HYMES, D.H. 1971. On communicative competence, In: Pride \& Holmes (eds.). 1972. LE ROUX, T.H. s.j. Gedagtes oor ons taal. Pretoria, V. \& R-drukkery.

PRIDE, J.B. \& HOLMES (eds). 1972. Sosiolinguistics. Penguin.

ROUX, A.AJ. 1967. Die vaktaal en die wetenskap, in: Referate (Vaktaalkongres van die SA Akademie).

STEYN,J.C. 1977. Die Afrikaner en Afrikaans. TGW, 17.

RUDOLPH, C.F. 1977. Taal as werktuig. Onderwy sbulletin, XXI.2.

TERBLANCHE, HJ. 1963. Nuwe vakwoorde in Afrikaans, in: BOTHA (red.), 1963. 